\title{
Suomen viljelysmaiden sinkkipitoisuudesta
}

\author{
MARTTI KURKI \\ Viljavuuspalvelu Oy, Helsinki
}

\section{On the zinc content of tilled soils in Finland}

\author{
MartTi Kurki \\ Viljavuuspalvelu Oy (Soil Testing Service), Helsinki, Finland
}

\begin{abstract}
In the years 1971 - 1973, zinc determinations were made in the laboratories of the Soil Testing Service in Helsinki, Finland, from 629 soil samples, representing different types of soil and different parts of the country.

For zinc determination the samples were ashed and dissolved in $2 \mathrm{~N}$ hydrochloric acid. Zinc was determined with an atomic absorption spectrophotometer.

The highest zinc contents were found in soils of high clay content. With increasing coarseness, the zinc content of mineral soils diminishes, being lowest in sandy soils. Taking into account all soils, the lowest contents were found in peat soils. The contents were higher in peat containing remains of trees than in other types of peat.

The zinc content was lowest in northern Finland, owing to the prevalence in that region of peat soils and coarse mineral soils. The highest contents were registered in the clayey and silty areas of southern and southwestern. Finland, or the surroundings of the cities of Tampere, Turku, Lahti and Helsinki.
\end{abstract}

\section{Sinkin esiintymisestä}

Sinkki on sekä kasveille että eläimille välttämätön hivenaine. Sitä on maakuoren uloimassa osassa keskimäärin $0.013 \%$ (SAKSELA 1964). Vertailun vuoksi mainittakoon, että vastaava rautapitoisuus on $4.7 \%$ ja kuparipitoisuus $0.007 \%$. Sinkkiä tavataan luonnossa aina muihin alkuaineisiin, tavallisimmin rikkiin yhtyneenä. Tärkein sinkkimineraali on sinkkivälke. Muista mainittakoon sinkkisälpä, piikalmeija, vilmiitti ja frankliiniitti.

Kasvit ottavat sinkin maasta $\mathrm{Zn}^{* *}$-ionina. Sen konsentratio on maanesteessä varsin alhainen. Maan sinkkipitoisuus on yleensä alempi kuin vastaavien alkuperäiskivilajien. Emäksisistä kivilajeista syntyneissä maissa sinkkipitoisuudet ovat tavallisesti korkeammat kuin ns. happamista kivilajeista syntyneissä. Humuspitoinen pintamaa sisältää sinkkiä yleensä enemmän kuin syvemmät kerrokset (esim. SILLANPäÄ 1972) johtuen lähinnä biologisesta rikastumisesta. 
Sinkin käyttökelpoisuus maassa huononee $\mathrm{pH}: \mathrm{n}$ kohotessa ja puutteet ovat kasveissa useimmiten havaittavissa mailla, joiden $\mathrm{pH}$ on yli 6.0. Jotkut, kuten CAMP (1945), pitävät kriittisenä pH-arvona 5.5-6.5. On myös tutkijoita, joiden mielestä liukoisuusminimi on $\mathrm{pH}$ 7:n tienoilla (JA Mison 1943).

Typpilannoitus voi vaikuttaa sinkin käyttökelpoisuuteen. Tällöin ratkaisevaa on lannoitteen vaikutus maan $\mathrm{pH}$-arvoon. Niinpä ammoniumnitraatti ja ammoniumsulfaatti alentavat $\mathrm{pH}$-arvoa ja täten sinkin liukoisuus paranee. Sen sijaan natrium- ja kalsiumnitraatit kohottavat $\mathrm{pH}$-arvoa ja tällöin sinkin liukoisuus heikkenee.

Suomen maaperästä aikaisemmin tehtyjen tutkimusten mukaan sinkin kokonaispitoisuudet vaihtelevat yleensä muutamasta milligrammasta yli 200 milligrammaan/litra maata. Viljelysmaissa oli Vuorisen (1958) mukaan sinkkiä keskimäärin 36 ppm ja MÄKıт̦ı́ (1961) mukaan kivennäismaissa 6$100 \mathrm{ppm}$ ja eloperäisissä maissa jonkin verran vähemmän, yleensä alle $60 \mathrm{ppm}$. Luonnontilaisten turvemaiden sinkin kokonaispitoisuus on SALMEN (1963) mukaan yleensä 5.4-64 ppm. SillanpäÄN (1962 a) aineistossa, joka käsitti sekä viljeltyjä että luonnontilaisia maita, vaihteli sinkkipitoisuus kivennäismaissa $32-230 \mathrm{mg} / \mathrm{l}$ (keskim. $79 \mathrm{mg} / \mathrm{l}$ ) ja eloperäisissä maissa $3.5-103 \mathrm{mg} / \mathrm{l}$ (keskim. $20 \mathrm{mg} / \mathrm{l}$ ).

Liukoisen sinkin pitoisuudet riippuvat olennaisesti käytetystä analyysimenetelmästä. VIro (1955 b) totesi Suomen metsämaissa olevan 0.05-M EDTA-liukoista sinkkiä $2.4-10$ ppm. Happameen ammoniumasetaattiin liukenevan sinkin määrät vaihtelevat 0.2 ja $20 \mathrm{mg} / \mathrm{l}$ välillä (SILLANPäÄ ja LAKANEN 1966). Edelliseen uuttonesteeseen lisätty EDTA ei paljoakaan vaikuta sinkin pitoisuuksiin. Sillä saaduista sinkkipitoisuuksista $80 \%$ jää välille 1-6 mg/1 (SillanPÄ̈̈ et al. 1974)

\section{Tutkimuksen suoritus ja menetelmät}

Vuosina 1971-1973 sinkkimäärityksiä tehtiin 629 maanäytteestä, jotka edustavat eri maalajeja ja Suomen eri osia. Määritysten lukumäärä on vielä niin vähäinen, ettei kovin pitkälle meneviä johtopäätöksiä voi tehdä, mutta jonkinlaisia viitteitä seuraavassa esitettävät tulokset kuitenkin antanevat.

Maanäytteet otettiin muokkauskerroksesta vähintään viitenä osanäytteenä. Näytteenoton yhteydessä määritettiin maalaji ja multavuus. Nämä määritykset tarkistettiin vielä laboratoriossa. Laboratoriossa näytteet kuivattiin ilmakuiviksi, minkä jälkeen ne jauhettiin ja seulottiin $2 \mathrm{~mm}$ seulan läpi. Viljavuustutkimuksessa sinkki määritetään tuhkasta käyttäen uutosnesteenä 2-n suolahappoa. Varsinainen määritys tapahtuu atomiabsorptiospektrofotometrillä. Käytetty menetelmä on valittu lähinnä sen takia, että myös eräät muut hivenravinteet, kuten kupari, määritetään samalla tavalla. Onko menetelmä paras mahdollinen, se seikka kaipaa lisätutkimuksia. Ehkä tämän menetelmän rinnalla olisi hyvä käyttää myös heikompaa uutosnestettä, jotta saataisiin selville lähinnä kasveille käyttökelpoinen sinkki. Useissa muissa maissa käytețäänkin heikompia uutosnesteitä vaihtuvan eli kasveille käyttökelpoisen sinkkimäärän selvittämiseksi. Käytössä on hyvin erilaisia uuttonesteitä, joista 


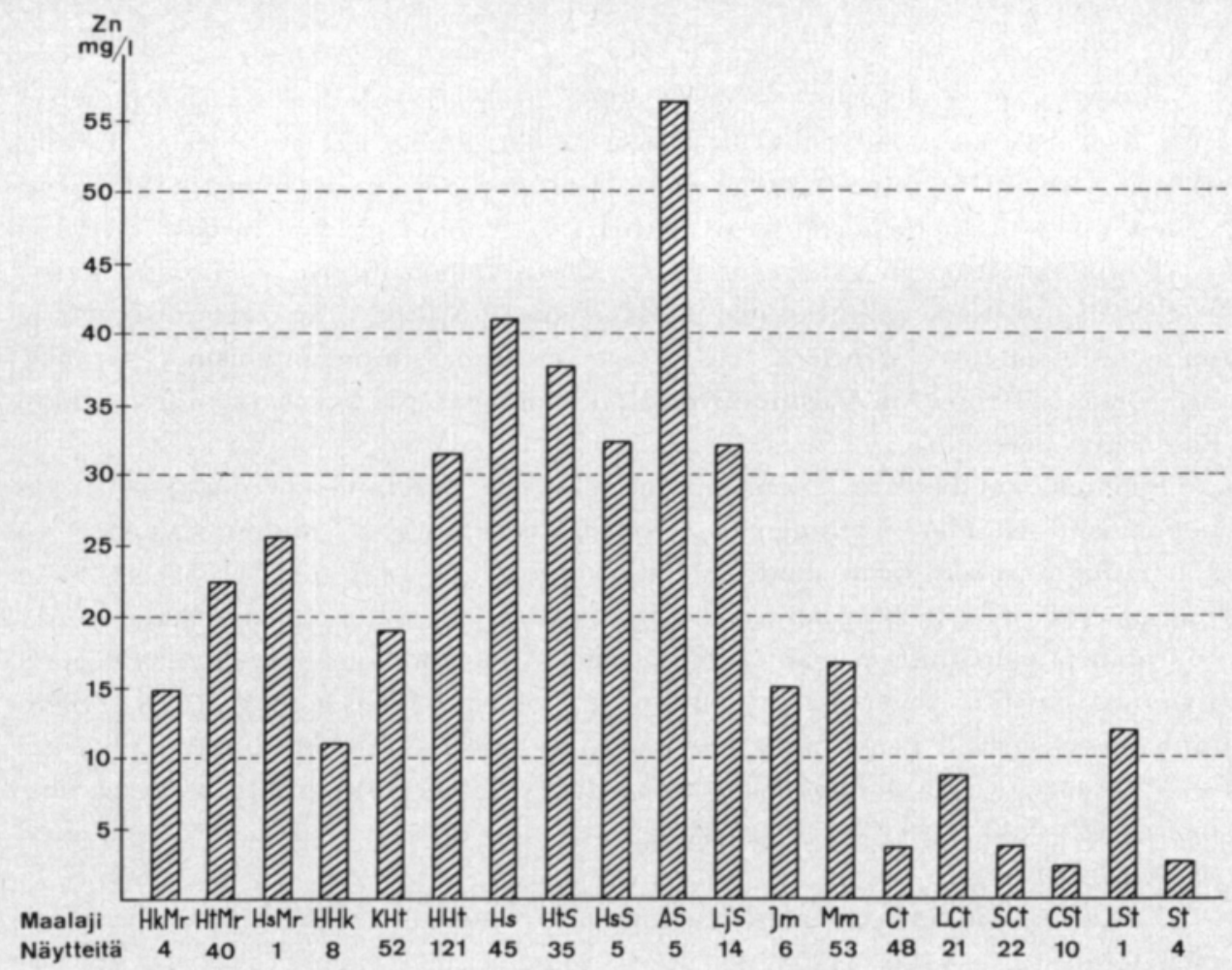

Kuva 1. Peltomaiden happoliukoisen sinkin pitoisuus maalajeittain.

Fig. 1. The content of acid-soluble zinc in Finnish field soils, by types of soil. $\mathrm{HkMr}, \mathrm{HtMr}$, $\mathrm{HsMr}=$ Moraine soils. $\mathrm{HHk}, \mathrm{KHt}, \mathrm{HHt}=$ Sand Soils. $\mathrm{Hs}=$ Silt, $\mathrm{HtS}, \mathrm{HsS}, \mathrm{AS}, \mathrm{LjS}=$ Clay soils. $\mathrm{Jm}=$ Mud soils. $\mathrm{Mm}=$ Mould. $\mathrm{Ct}, \mathrm{LCt}, \mathrm{SCt}=$ Carex peat soils. $\mathrm{CSt}, \mathrm{LSt}, \mathrm{St}=$ Spagnum peat soils.

mainittakoon 0.5-n KCl, ammoniumasetaatti ( $\mathrm{pH} 4.6$ ), 0.1-n magnesiumsulfaatti, 0.1-n HCl, 0.05-m EDTA-liuos (VIRO 1955 a) ja lisäksi on käytetty Aspercillusmenetelmää eli biologista menetelmää. Kuitenkin on todettu, että vaihtuva sinkki korreloituu melko hyvin kokonaissinkin kanssa ja tämän vuoksi Suomessa viljavuustutkimuksen yhteydessä käytetty menetelmä puolustaneekin paikkaansa. Joka tapauksessa olisi meillä syytä vertailun vuoksi suorittaa määrityksiä heikommilla uutosnesteillä ja verrata tuloksia myöskin kenttäkokeisiin.

\section{Sinkkipitoisuus peltomaissa}

Eri maalajien sinkkipitoisuus

Eri maalajien happoliukoisen sinkin pitoisuus esitetään kuvassa 1. Selvästi korkein sinkin pitoisuus on aitosavessa, eli $\mathbf{5 6 , 8} \mathrm{mg}$ maalitraa kohti. Hietasavessa pitoisuus on 37.9 ja hiesusavessa $32.4 \mathrm{mg}$. Aitosaven jälkeen korkein pitoisuus on todettu hiesumaissa, joiden keskiarvo on $41.4 \mathrm{mg}$. Raekoon suurentuessa sinkkipitoisuus alenee ollen hienohietamaissa 31.6, karkeassa hiedassa 19.2 ja hienossa hiekassa 11.0. Sama aleneva suunta näkyy moreeni- 


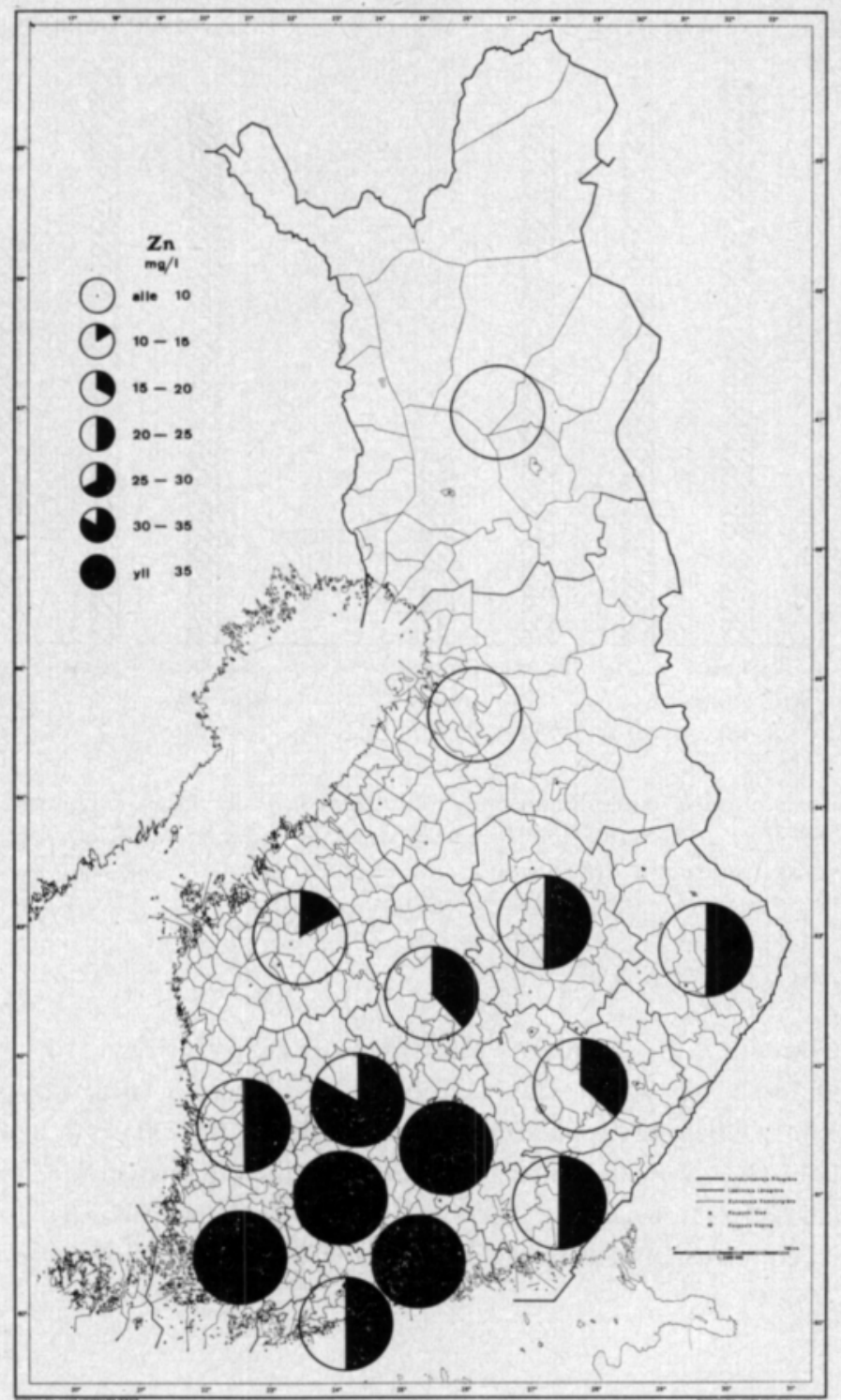

Kuva 2. Peltomaiden happoliukoisen sinkin pitoisuus alueittain. Fig. 2. The content of acid-soluble zinc in field soils, by regions.

maissa. Niinpä hiesumoreenissa pitoisuus on 25.8, hietamoreenissa 22.4 mutta hiekkamoreenissa vain 12.7. Samanlainen suuntaus on todettu myös sinkin totaalimäärissä (SILlAnPÄÄ 1962 b). Järvimuta- ja multamaissa pitoisuudet ovat suurin piirtein samaa luokkaa kuin karkeimmissa kivennäismaissa. Turvemaissa sinkkipitoisuudet ovat selvästi alimmat. Kuitenkin sinkkiä on enemmän puujätettä sisältävissä turpeissa kuin muissa turpeissa. Niinpä metsäsaraturpeen (LCt) sinkkipitoisuus on 8.8, mutta saraturpeen 3.4 ja rahkaturpeen 2.5. Suhde eri maalajien välillä muistuttaa tilannetta kalin ja kuparin kohdalla (KURKI 1972). 


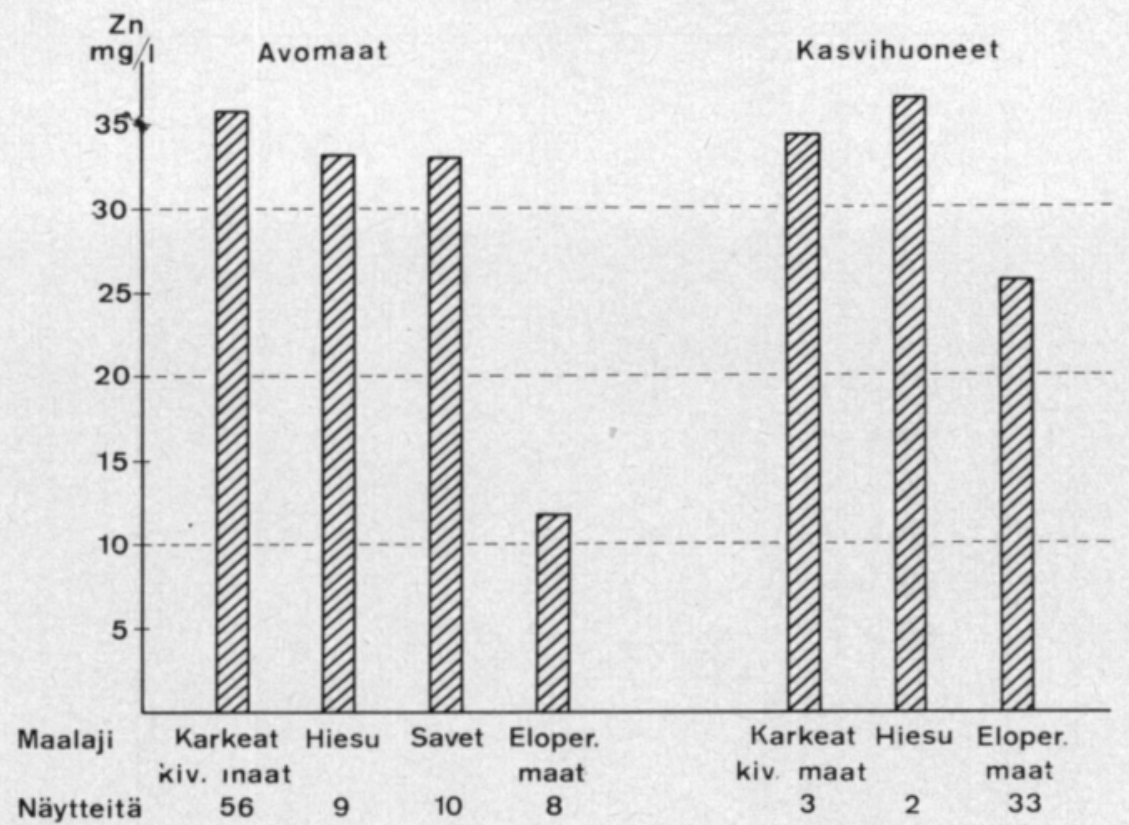

Kuva 3. Puutarhamaiden happoliukoisen sinkin pitoisuus eri maalajiryhmissä.

Fig. 3. The content of acid-soluble zinc in garden soils by different soil categories. Avomaat = Open ground. Kasvihuoneet $=$ Greenhouses. Karkeat kiv.maat $=$ Coarse mineral soils. Hiesu $=$ Silt. Savet $=$ Clay soils. Eloper. maat $=$ Organogenic soils.

Kivennäismaan multavuuden vaikutusta sinkkipitoisuuteen ei tässä tulosten yhteenvedossa ole selvitetty. Ulkolaisten lähteiden mukaan sinkkipitoisuus kuitenkin kohoaa kivennäismaan multavuuden lisääntyessä. Monien muiden ravinteiden kohdalla tilanne on niin, että humuspitoisuuden lisääntyessä kivennäismaissa ravinnețilanne kasvaa, ollen korkeimmillaan runsasmultaisessa tai erittäin runsasmultaisessa luokassa (SIllanPäÄ 1962 b), KURKI 1972).

\section{Sinkkipitoisuus alueittain}

Alueittaiset sinkkipitoisuudet käyvät ilmi kuvasta 2. Siitä nähdään, ețtä korkeimmat keskimääräiset sinkkipitoisuudet ovat Itä-Hämeen, VarsinaisSuomen, Hämeen läänin, Uudenmaan ja Pirkanmaan maatalouskeskusten alueilla. Alimmat pitoisuudet sen sijaan ovat Lapin, Oulun ja Etelä-Pohjanmaan maatalouskeskusten alueilla. Edellämainittu toteamus koskee kaikkia maalajeja. Jos verrataan saman maalajin pitoisuuksia eri alueilla, niin todetaan mm. seuraavaa: Korkeimmat karkeiden kivennäismaisen pitoisuudet tavataan Itä-Hämeessä, Uudellamaalla ja Hämeenläänissä. Alimmat sen sijaan Kymenläänissä, Etelä-Pohjanmaalla, Lapissa, Oulunläänissä ja PohjoisKarjalassa. Korkeimmat eloperäisten maiden pitoisuudet on saatu Pirkanmaalle, Kuopion lääniin ja Pohjois-Karjalaan. Sen sijaan alimmat pitoisuudet ovat Oulun, Lapin, Etelä-Pohjanmaan ja Keski-Suomen maatalouskeskusten 
alueilla. Valitettavasti määritysten lukumäärä on niin pieni, etței mitään pitkälle meneviä johtopäätöksiä eri alueiden välillä voida tehdä.

\section{Puntarhamaiden sinkkipitoisuus}

Puutarhamaista sinkkimäärityksiä on tehty verraten vähän. Kuvassa 3 on esitetty eri maalajiryhmien sinkkipitoisuudet sekä avomaalla että kasvihuoneissa. Avomailla karkeiden kivennäismaiden sekä hiesu- ja savimaiden keskimääräiset sinkkipitoisuudet ovat samaa suuruusluokkaa, eli $33-36 \mathrm{mg}$ maalitraa kohti, sen sijaan eloperäisten maiden pitoisuus on selvästi alempi eli 11.6 mg. Lasinalaisilla viljelyksillä karkeiden kivennäismaiden ja hiesumaiden pitoisuudet ovat samaa suuruusluokkaa kuin avomaillakin. Eloperäisten maiden pițoisuus on kuitenkin korkeampi kuin vastaavasti avomailla, ollen keskimäärin $25.8 \mathrm{mg}$. Tämä johtunee sinkkiä sisältävän hivenseoksen käytöstä kasvihuoneviljelyssä.

\section{Yhteenveto}

2-n suolahappoon liukenevan sinkin pitoisuus on korkein aitosavimaissa ja sen jälkeen hiesumaissa. Kivennäismaan muuttuessa karkeammaksi sinkkipitoisuus alenee ollen alin hiekkamaissa. Kaikista maalajeista alimmat pitoisuudet ovat turvemaissa. Metsäturpeissa pitoisuudet ovat korkeammat kuin muissa turvelajeissa.

Sinkkipitoisuus on pohjois-Suomessa alin johtuen siellä vallitsevista turvemaista ja karkeista kivennäismaista. Korkeimmat pitoisuudet ovat eteläja lounais-Suomen savi- ja hiesualueilla.

\section{KIRJALLISUUTTA}

CAмp, A. F. 1945. Zinc as a nutrient for plants. Soil Sci. 60: 157-164.

Jamison, V. C. 1943. The effect of particle size of copper- and zinc-source materials and of excessive phosphates upon the solubility of copper and zinc in a Norfolk fine sand. Soil Sci. Soc. Amer. Proc. 8: 323-326.

KURKI, M. 1972. Suomen peltojen viljavuudesta II. Referat: Über die Fruchtbarkeit des finnischen Ackerbodens auf Grund der in den Jahren 1955-1970 durchgeführten Bodenfruchtbarkeitsuntersuchungen. 182 p. Helsinki

LEH, H. 1969. Zink. Handbuch der Pflanzenkrankheiten. Band I. p. 289-333. Berlin

Мӓкıтıє, О. 1961. Eräiden hivenaineiden esiintymisestä viljelysmaissamme. Summary: The occurence of some trace elements in arable soils in Finland. Agrogeol. publ. 78: 1-25.

Sанама, TH. G. 1946. Geokemia. 447 p. Helsinki.

Saksela, M. 1964. Malmit. Suomen geologia. p. 125-187. Helsinki.

SALMI, M. 1963. On the influence of geological factors upon the plant nutrient content of peats. J. Scient. Agric. Soc. Finl. 35: 1-18. 
Sillanpä̈, M. 1962 a. On the effect of some soil factors on the solubility of trace elements. Agrogeol. Publ. 81: 1-24.

$-1962 \mathrm{~b}$. Trace elements in Finnish soils as related to soil texture and organic matter content. J. Scient. Agric. Soc. Finl. 34: 34-40.

-1 1972. Distribution of trace elements in peat profiles. Reprint from the Proceedings of the 4 th International Peat Congress I-IV. Helsinki 1972.

- - \& Lakanen, E. 1966. Readily soluble trace elements in Finnish soils. Ann. Agric. Fenn. 5: 298-304.

- - Lakanen, E. 1969. Trace element contents of plants as a function of readily soluble soil trace elements. J. Scient. Agric. Soc. Finl. 41:60-67.

- - Lakanen, E. \& VirRi K. 1974. Hivenaineiden uutto EDTA:lla tehostetulla happamella ammoniumasetaatilla suomalaisista maista. Kehittyvä Maatalous (painossa).

VIRo, P. J. 1955 a. Use of ethylenediaminetetraacetic acid in soil analysis. I. Experimental. Soil Sci. 79: 459-465.

- 1955 b. Use of ethylenediaminetetraacetic acid in soil analysis. II. Determination of soil fertility. Soil Sci. 80: $69-74$.

VUorinen, J. 1958. On the amounts of minor elements in Finnish soils. J. Scient. Agric. Soc. Finl. 30: 30-35. 